\title{
Microalgal Lipid Extraction and Evaluation of Single-Step Biodiesel Production
}

\author{
Chattip Prommuak ${ }^{1}$, Prasert Pavasant ${ }^{1}$, Armando T. Quitain ${ }^{2}$, Motonobu Goto ${ }^{3}$, \\ and Artiwan Shotipruk ${ }^{1, *}$ \\ 1 Chemical Engineering Research Unit for Value Adding of Bioresources, Department of Chemical \\ Engineering, Faculty of Engineering, Chulalongkorn University, Phayathai Road, Patumwan, Bangkok \\ 10330, Thailand \\ 2 Graduate School of Science and Technology, Kumamoto University, Kumamoto 860, Japan \\ 3 Department of Chemical Engineering, Graduate School of Engineering, Nagoya University, Furo-cho, \\ Chikusa-ku, Nagoya, 464-8603, Japan \\ *E-mail:artiwan.sh@chula.ac.th
}

\begin{abstract}
This work examined solvent extraction of lipid from microalgae for production of renewable biofuels, thereby allowing appropriate selection of solvent and extraction methods. The results of this study revealed that the mixture of chloroform and methanol $(\mathrm{C} / \mathrm{M})$ at the ratio of $2: 1(\mathrm{v} / \mathrm{v})$ could extract the highest amount of total lipid from algae, while hexane was found to be a good solvent, concerning the selectivity for targeted lipids such as mono-, di- and tri-glycerides. As far as the extraction methods are concerned, applying disruption, especially with microwave could accelerate the rate of lipid extraction from algae with tough cell walls such as Chlorella vulgaris. On the other hand, ultrasound and microwave assisted extraction techniques added no benefits to the extraction of lipid from powder of Haematococcus pluvialis whose cell wall was previously damaged. Other than lipid extraction, this paper concerns with the development of transesterification process for algal lipid using C. vulgaris as a model system. Here, the effects of the amount of catalyst, alcohol to biomass ratio and reaction time on biodiesel yield were investigated. We also studied a single-step biodiesel production where extraction and transesterification simultaneously took place and comparison between this method and the conventional two-step biodiesel production process was made.
\end{abstract}

Keywords: Microalgae, biodiesel, lipid, solvent extraction, transesterification.

ENGINEERING JOURNAL Volume 16 Issue 5

Received 20 February 2012

Accepted 16 June 2012

Published 1 October 2012

Online at http://www.engj.org/

DOI:10.4186/ej.2012.16.5.157 


\section{Introduction}

Biodiesel, alternative energy produced from transesterification of vegetable oils or animal fats, has played a key role in overcoming energy depletion crisis since it is a renewable and environmentally friendly fuel. Beyond oleaginous plants, microalgae are an interesting raw material sources for biodiesel due to their high growth rates, high lipid contents and requirement of smaller cultivation area [1]. However, the production of energy from microalgae is still uneconomical. One of the production steps that consumes the highest energy, but has not yet been adequately informed, is the step of the extraction of oil from the algal cells [2].

Different strains of algae have different structures and compositions. In some, the oil can easily be extracted, while in some others, the oil may be contained within the cells, enveloped by tough cell walls which need to be cracked a priori. Among several extraction methods, maceration is the most traditional and the simplest extraction procedure. Some drawbacks of this method include long extraction time, low mass transfer and low yield, despite the low cost of production. Other than maceration, several extraction techniques have later on been developed. Among those, cavitational effects from ultrasound assisted extraction (UAE) and intracellular heating from microwave assisted extraction (MAE) have been found to cause damage to cell walls, shortening the time needed for extractions [3]. As for biodiesel production via transesterification, for the past decade, there has been an exponentially rising number of studies aiming to improve the design of the transesterification process as well as optimizing the operating parameters, e.g. reaction conditions, alcohol to oil ratio, choices of catalyst. While these work are in search of efficient methods for extraction of microalgal lipids for the generate biodiesel, others propose quite interesting alternative approach of an in situ or single step transesterification without a need of prior tedious extraction step [4].

The aim of this study was therefore to examine various methods for microalgal lipid extraction of selected algal strains such as $\mathrm{H}$. pluvialis and C. vulgaris. The objectives include the study of the effect of different solvents and extraction methods on the extracted lipid yield. Additionally, we also investigated the suitable operating parameters for two-step biodiesel production and compare its potential with the direct single-step method.

\section{Experimental}

\subsection{Biomass and Sample Preparation}

Dried powder of H. pluvialis was purchased from Cyanotech Corporation, Hawaii Ocean, Science and Technology Park, USA. C. vulgaris were cultivated in an airlift photobioreactors under outdoor condition (temperature of $28-34^{\circ} \mathrm{C}$ and daily solar cycles with light intensity of 0-100 klux) at the Department of Chemical Engineering, Chulalongkorn University, Thailand. With Thailand Fishery medium and aeration of $10 \mathrm{~L} / \mathrm{min}$, the microalgae reached the end of log-phase growth and were harvested on day 4 of the cultivation. The paste were obtained by centrifugation of the suspension (at $4500 \mathrm{rpm}$ for $10 \mathrm{~min}$ ) followed by lyophilization. For the study of transesterification, the lyophilized cells of $C$. vulgaris were used. All samples were stored at $4^{\circ} \mathrm{C}$ until used.

\subsection{Methods for Lipid Extraction}

Various extraction methods such as Soxhlet extraction, maceration, UAE and MAE were investigated for their effects on the yield and composition of the extracted lipid. The procedure and the conditions examined for each method are provided as follows. For all methods, each extract was filtered using a filter paper to remove biomass residue. The filtered solution was then evaporated, and the remaining crude lipid was gravimetrically measured.

\subsubsection{Soxhlet Extraction}

Soxhlet extraction was assumed to be the method that could completely extract all the lipids presented in microalgae, resulting in 100\% recovery. Thus, the amounts of lipid extracted from other methods are reported based on the one extracted by this method. Here, one gram of algae was extracted for $4 \mathrm{~h}$ by 180 $\mathrm{ml}$ of solvent in a Soxhlet apparatus. The effects of two different solvents were studied, i.e. hexane (Fisher 
Scienctific Ltd.) and the mixture of chloroform (RCI labscan Ltd.) and methanol (MeOH) (Mallinckrodt Chemicals Inc.) at 2:1 v/v. The ratio was developed by Folch et al., 1957 [5] based on the principle that the lipid extraction solvent must be adequately polar to remove lipids from their association with cell membranes and tissue constituents but also not so polar that the solvent does not readily dissolve all triacylglycerols and other nonpolar lipids [6].

\subsubsection{Maceration}

The experiment was carried out by charging microalgae and solvent $(1: 100 \mathrm{w} / \mathrm{v})$ into an Erlenmeyer flask. The choice of solvent used in this experiment was based on the investigation of solvent types described above. Carried out at room temperature $\left(30^{\circ} \mathrm{C}\right)$, stirring was provided manually at the beginning, followed then by maceration through stagnant liquid.

\subsubsection{UAE}

To start the experiment, the biomass and the same selected solvent $(1: 100 \mathrm{w} / \mathrm{v})$ was loaded into a conical flask. The flask was then rapidly placed into a $40 \mathrm{kHz}$ ultrasonic bath, Crest Ultrasonics. The extraction was performed at room temperature $\left(30^{\circ} \mathrm{C}\right), 40^{\circ} \mathrm{C}$ or $50^{\circ} \mathrm{C}$ for $5-30 \mathrm{~min}$.

\subsubsection{MAE}

The experiment was carried out using a microwave extractor, MARS 5, CEM Corp. (Mathews, NC, USA). Biomass and solvent with the ratio of 1:100 (w/v) was charged into the vessel. The effects of extraction time and temperature on the amount of lipid extracted were studied at $5-30 \mathrm{~min}, 40-50^{\circ} \mathrm{C}$, respectively while the maximum power of the apparatus was kept constant at $300 \mathrm{Watt}$.

\subsection{Analysis of lipid extracted from different solvents}

To select the suitable solvent for microalgal lipid extraction, the crude lipids extracted by hexane and $\mathrm{C} / \mathrm{M}$ were converted to biodiesel. The amount of biodiesel was quantified by GC-MS following the standard method of AOAC (2005) [7]. That is, $2 \mathrm{~g}$ of crude lipid extracted by hexane and C/M was saponified by 25 $\mathrm{ml} 0.5 \mathrm{M}$ methanolic $\mathrm{NaOH}$. Then, $300 \mathrm{mg}$ of the saponified lipid sample was treated with $8 \mathrm{ml} \mathrm{of}_{\mathrm{BF}_{3}-}$ methanol and boiled for 2-4 min. Thereafter, $2-3 \mathrm{ml}$ of petroleum ether $\left(60^{\circ} \mathrm{C}\right)$ was added to resultant solution to dissolve the esters. Sufficient amount of saturated $\mathrm{NaCl}$ aqueous solution was then added to allow the FAMEs to float to the top of the flask, which was collected for analysis.

\subsection{Transesterification of Microalgal Lipid}

\subsubsection{Conventional Two-step Biodiesel Production}

In the two-step production, transesterification was carried out on the lipid previously extracted from 3 grams of dry microalgae with $\mathrm{C} / \mathrm{M}$ using Soxhlet apparatus, following the method described in section 2.2.1. Into a vessel equipped with a condenser, the extracted oil was charged along with the alkoxide solution of $\mathrm{KOH}$ alkali catalyst (Wako, Japan) (2-8\% by weight of algae) and methanol at various methanol to algal biomass $\mathrm{v} / \mathrm{w}$ ratios $(8: 1,12: 1$ and $16: 1)$. The mixture was heated to a controlled temperature of $60^{\circ} \mathrm{C}$. The reaction was allowed to take place for $1,2,3$ or $4 \mathrm{~h}$. The vessel was cooled to room temperature to stop the reaction. Phase separation was subsequently carried out following the method of Folch et al. (1957) [5]. Here, chloroform and water were added into the mixture at the ratio of mixture:chloroform:water of 10:10:9. After shaken vigorously, the mixture was centrifuged at $2000 \mathrm{rpm}$ for $10 \mathrm{~min}$, resulting in separation into two phases. Methanol, the by-product glycerol and other polar impurities that dissolved in water formed the upper phase while fatty acid methyl esters (FAMEs), free fatty acids (FFAs), lipids and other non-polar compounds well dissolved in the chloroform bottom phase, which was collected for further GC analysis.

\subsubsection{Single-Step Biodiesel Production}


The single-step method was carried out with 3 grams of dried algae charged into the vessel, in which the catalyst, alcohol and solvent were added to allow the extraction of lipid and the transesterification to take place simultaneously. To compare its performance with the conventional two-step biodiesel production, a selected condition was used for both methods, which was transesterification at $4 \%$ of catalyst, $16: 1(\mathrm{v} / \mathrm{w})$ ratio of alcohol to biomass and the reaction time of $2 \mathrm{~h}$. After the reaction, the biomass was filtered out by a No. 5 Whatman paper. Phase separation was carried out and the biodiesel product was collected following the method previously described in section 2.4.1.

\subsection{GC Analysis of Biodiesel}

The products obtained from the experiment as described in section 2.4 were analyzed for the amounts of FAMEs using gas chromatography (GC), Shimadzu GC-14B, equipped with a flame ionization detector (FID) in which 0.1 microliter of the sample was injected into the column. Separation of the sample products was achieved by a capillary column (CP-FFAP CB, $25 \mathrm{~m}$ (length), $0.32 \mathrm{~mm}$ (ID), $0.3 \mu \mathrm{m}$ (film thickness)), Varian, California. Injector and detector temperatures were set at $270^{\circ} \mathrm{C}$ and $300^{\circ} \mathrm{C}$, respectively. The elution temperature program had an initial temperature of $100^{\circ} \mathrm{C}$ holding for 5 min prior to linearly ramping with the rate of $10^{\circ} \mathrm{C} / \mathrm{min}$ to the final temperature of $250^{\circ} \mathrm{C}$. The final temperature was then held for $20 \mathrm{~min}$, making the total run time of $40 \mathrm{~min}$. The quantifications of the sample were calculated using methyl heptadecanoate as an internal standard. The yield of FAME are reported in two different units, defined by Eqs. (1) and (2) as follows:

FAME Yield $(\%$ by weight of algae $)=\frac{\text { weight of FAME obtained after tranesterified }}{\text { weight of algae input }} \times 100$

FAME Yield (\%by weight of crude lipid) $=\frac{\text { weight of FAME obtained after tranesterified }}{\text { weight of crude lipid Soxhlet extracted with } \mathrm{C} / \mathrm{M}} \times 100$

\section{Results and discussion}

\subsection{Effect of Extraction Solvent}

In determining lipid content of algae, several works were carried out extraction commonly using $\mathrm{C} / \mathrm{M}$ as a solvent [8-10] while in some others hexane was employed [11-12]. The lipid contents were often reported as the weight ratio of the crude extract and the dry biomass. In fact, the crude extract cannot all turn into biodiesel as the solvents might dissolve also some impurities. This investigation clarifies which of those two solvents is actually more suitable for the extraction of microalgal lipid which is further used as feedstock for biodiesel production. As shown in Table 1, the amount of the crude extract obtain from the two solvent are greatly different. C/M gave higher yield of crude extract, $38.90 \% \mathrm{w} / \mathrm{w}$ of algal biomass while $20.28 \%$ was obtained with extraction by hexane. This is because $\mathrm{C} / \mathrm{M}$ is a mixture of polar (methanol) and non-polar (chloroform) solvents, thus both neutral and polar lipids could then be extracted. On the other hand, such non-polar solvent as hexane could preferably dissolve only non-polar lipids in the microalga. After tranesterified, chromatographic analysis shows that $33.3 \%$ and $44.3 \%$ of the crude lipid extracted with $\mathrm{C} / \mathrm{M}$ and hexane, respectively, could be converted to biodiesel. This indicates that although smaller amount of crude extract was obtained with hexane, it is a better solvent in terms of selectivity for targeted lipid such as mono-, di- and tri-glycerides. Other impurities in the crude extract are such as FFA and pigments (data not shown). However, C/M still gave higher amount of biodiesel by weight of algae, and it was therefore used in subsequent investigations. 
Table 1. Amount of crude lipid extracted with hexane and $\mathrm{C} / \mathrm{M}$ and amount of biodiesel obtained from corresponding extracted lipids.

\begin{tabular}{lccr}
\hline Solvent & $\begin{array}{c}\text { Amount of crude } \\
\text { extract (\% by wt of } \\
\text { algae) }\end{array}$ & $\begin{array}{c}\text { Amount of biodiesel } \\
\text { (\% by wt of crude }_{\text {lipid) }}^{\mathbf{b}}\end{array}$ & $\begin{array}{r}\text { Amount of biodiesel } \\
\text { (\% by wt of algae) } \\
(\mathbf{a x ~ b )} / \mathbf{1 0 0}\end{array}$ \\
\hline C/M & 38.9 & 33.3 & 13.0 \\
hexane & 20.3 & 44.3 & 9.0 \\
\hline
\end{tabular}

\subsection{Comparison of Extraction Methods}

In this experiment, the effects of ultrasonic cavitation and molecular heating from microwave were investigated for lipid extraction of two algal strains: H. plwialis and C. vulgaris. The performance of each method was evaluated by means of lipid recovery based on Soxhlet extraction. As shown in Fig. 1, the result indicates that for the short period of UAE $(5-10 \mathrm{~min})$, the amount of lipids recovered slightly increased with increasing temperature, from 30 to $40^{\circ} \mathrm{C}$. On the other hand, the lipid yield decreased with increasing UAE duration (from 15 to $30 \mathrm{~min}$ ). It is therefore possible that ultrasound could accelerate the oxidation reaction of some fatty acids [13]. Thus, the decrease of lipid recovery was possibly due to the damage of some substance in the cells when applying ultrasound for longer duration. Although it is likely that MAE gave the highest extraction rate in this study and the rate tended to increase with the increase in extraction temperature, only slightly benefit was found from the method. This was probable that the purchased $H$. plwivilis used in this study was already cracked during the manufacturing process of powder production. Hence, there was no cell wall resistance and the rate of extraction would therefore be mainly affected by the solute solubility in the solvent.

The above hypothesis was supported by the lipid extraction results of the cultivated C. vulgaris, whose cell wall remained intact. Here, the same three methods, maceration UAE and MAE were investigated. As shown in Fig. 2, it is obvious that without applying of cell disruption techniques, maceration resulted in slowest extraction rate. Although the increase in maceration temperature might help enhance the extraction, the percentage of lipid recovery is likely to be limited at approximately $70 \%$, even after the extraction time as long as $120 \mathrm{~min}$. On the other hand, both UAE and MAE resulted in better extraction since the time required to reach the same amount of lipid was shortened. Comparing among these two techniques, MAE seems to be favourable for extraction of lipid from C. vulgaris as it resulted in higher lipid recovery, even when operated at the lower temperature. The maximum lipid recovery in this study $(82 \%)$ was obtained from MAE for $30 \mathrm{~min}$ at the extraction temperature of $50^{\circ} \mathrm{C}$.

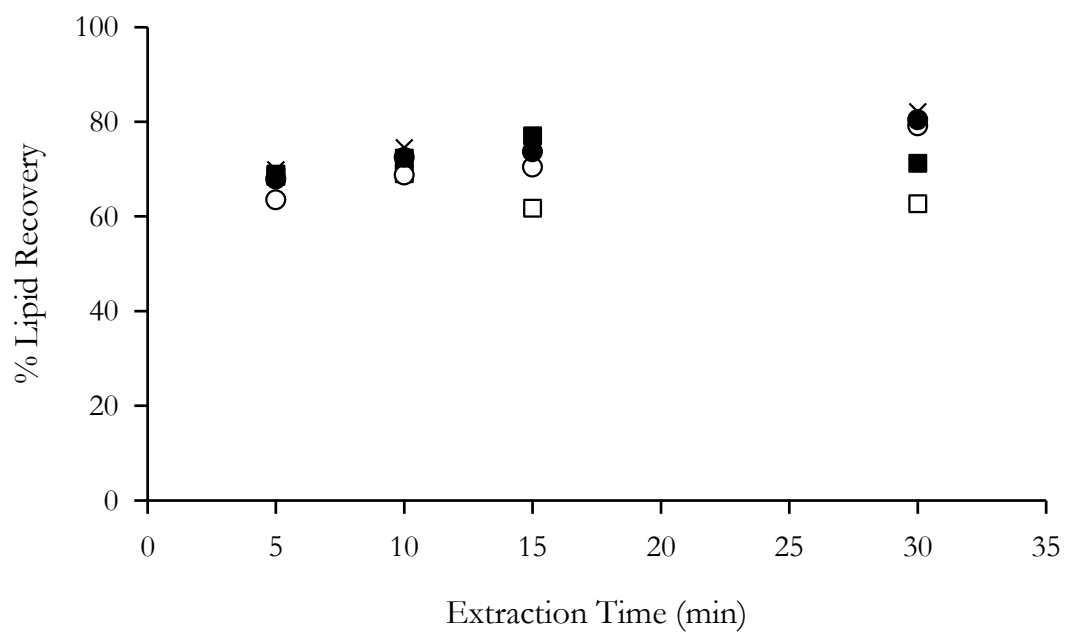

Fig. 1. Comparison of $\%$ lipid recovery from $H$. plwialis using three different extraction methods, maceration at $30(\mathrm{O})$ and $40^{\circ} \mathrm{C}(\bullet)$, UAE at $30(\square)$ and $40^{\circ} \mathrm{C}(\boldsymbol{\square})$ and MAE at $40(\times)$ (Replication of experiments was carried out for selected conditions. The standard deviations of \%lipid recoveries vary from \pm 0.2 to 3.5 . 


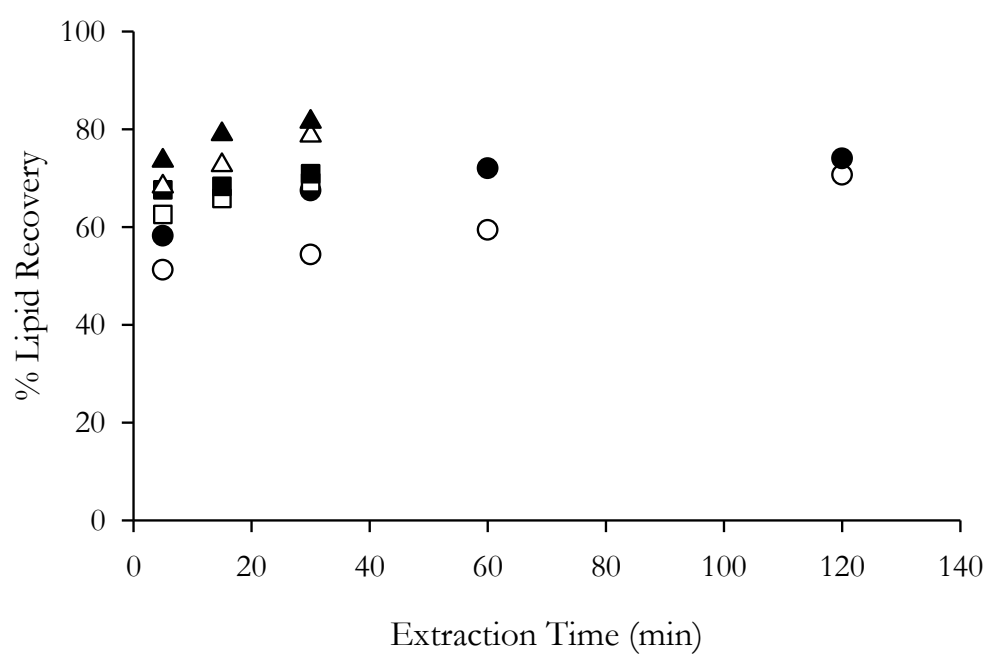

Fig. 2. Comparison of $\%$ lipid recovery from C.vulgaris using different extraction methods: maceration at 40 $(\mathrm{O})$ and $50^{\circ} \mathrm{C}(\bullet)$, UAE at $40(\square)$ and $50^{\circ} \mathrm{C}(\boldsymbol{\square})$ and MAE at $40(\triangle), 50^{\circ} \mathrm{C}(\boldsymbol{\Delta})$. (Replication of experiments was carried out for selected conditions. The standard deviations of \%lipid recoveries vary from \pm 0.2 to 3.5 )

\subsection{Microalgal Biodiesel Productions}

\subsubsection{Fatty Acid Profile}

Fatty acid profile of $C$. vulgaris lipid was obtained from GC analysis of its biodiesel products. Table 2 shows the result that agrees with Lee et al. (2010) [3], which reported that the most abundant FAME from $C$. vulgaris was methyl linoleate, followed by methyl palmitate. Other than those two, a small amount of methyl oleate and stearate were found. These FAMEs were reported to be common components in biodiesel from crops [14]. Advantageously, among these FAMEs, methyl palmitate whose quantity ranked second in this study was established as one of biodiesel components that provide highest cetane response [14]. Table 2 also shows the determination of average molecular weights of fatty acids which can be used for further estimation of the molecular weight of microalgal crude lipid extract.

Table 2. Fatty acid profile of triglycerides extracted from C. vulgaris following maceration of algal biomass in $\mathrm{C} / \mathrm{M}$

\begin{tabular}{lccr}
\hline Fatty acid & $\begin{array}{c}\text { Molecular weight } \\
(\mathbf{g} / \mathbf{m o l})^{\mathbf{a}}\end{array}$ & $\begin{array}{c}\text { Distribution in } \\
\text { sample } \mathbf{( \% )} \mathbf{b}^{\mathbf{b}}\end{array}$ & $\mathbf{( a \times b ) / 1 0 0}$ \\
\hline Palmitic acid & 256.4 & 31.6 & 81.0 \\
Stearic acid & 284.5 & 3.1 & 8.8 \\
Oleic acid & 282.5 & 10.3 & 29.0 \\
Linoleic acid & 280.5 & 36.3 & 101.9 \\
Linolenic acid & 278.4 & 18.7 & 52.1 \\
\hline Average molecular weight of fatty acids & & 272.8 \\
\hline
\end{tabular}

With the formation of the triglyceride molecule facilitated by the combination of fatty acid molecules and a molecule of glycerol with the condensation of three molecules of water, the average molecular weight of the microalgae oil can be estimated to be $856.42 \mathrm{~g} / \mathrm{mol}$.

\subsubsection{Effects of Amount of Catalyst on Biodiesel Yield}

The effect of the amount of catalyst on the biodiesel yield is shown in Fig. 3 which illustrates the increase of biodiesel yield with the increasing amount of catalyst from 2 to $6 \%$. However, the yield was found to be decreased when excess amount of catalyst $(8 \%)$ was used. This is because excess amount of catalyst may 
also participate in saponification, causing the formation of water and soap, which interferes the transesterification reaction.

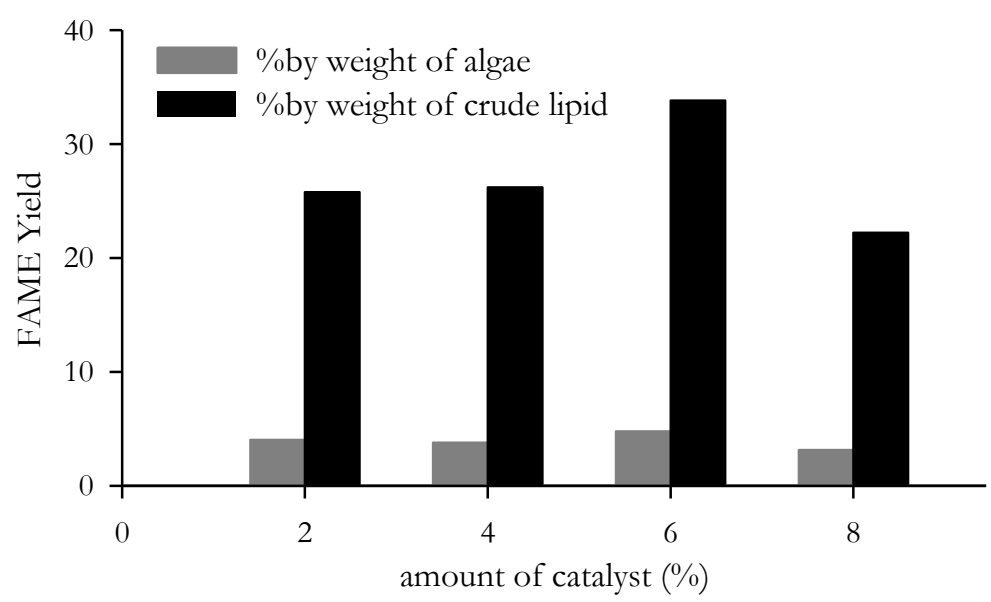

Fig. 3. Effect of amount of catalyst on biodiesel yield with fixed reaction time of $4 \mathrm{~h}$ and ratio of methanol to biomass of 16:1. (Replication of experiments was carried out for selected conditions. The standard deviations of FAME yields (\% by weight of lipid) vary from $0.8-3.0$.)

Overall, in terms of conversion, the percentages of FAMEs based on the crude lipid extracted were considered quite low. This can be explained by the fact that crude algal lipids extracted with $\mathrm{C} / \mathrm{M}$ contain many impurities such as chlorophylls, lutein fatty acid esters, free fatty acids, etc. Not only these could not be converted to biodiesel, they also interfere with the reaction. The result agrees with Montes D'Oca et al., 2011[15] which revealed similar yield of FAMEs obtained from transesterification of Chlorella pyrenoidosa lipid extracted with $\mathrm{C} / \mathrm{M}$.

\subsubsection{Effect of Reaction Time on Biodiesel Yield}

The effect of reaction time on biodiesel yield was determined at the fixed ratio of alcohol to biomass of 16:1 and the amount of catalyst loaded of 4\%. The result in Fig. 4 shows that the longer the reaction time, the higher the yields of FAMEs for the range of reaction time used in this study.

\subsubsection{Effect of Alcohol to Biomass Ratio}

Generally, increasing amount of alcohol would increase the rate of reaction, resulting in better yield in short duration [16]. However, as shown in Fig 5, the alcohol to biomass ratio presented no significant differences on the biodiesel yield for the range employed in this study. The alcohol to biomass $\mathrm{v} / \mathrm{w}$ ratio in the range used in this study was far greater than the theoretical ratio required for biodiesel conversion. That is, the theoretical 3:1 molar ratio for conversion of triglycerides, for example, is equivalent to only 1:100 (v/w) ratio. This was calculated based on the assumption that dry algae contained, on the average, $14 \%$ by weight of total lipid and $50 \%$ of which were suitable for biodiesel production. 


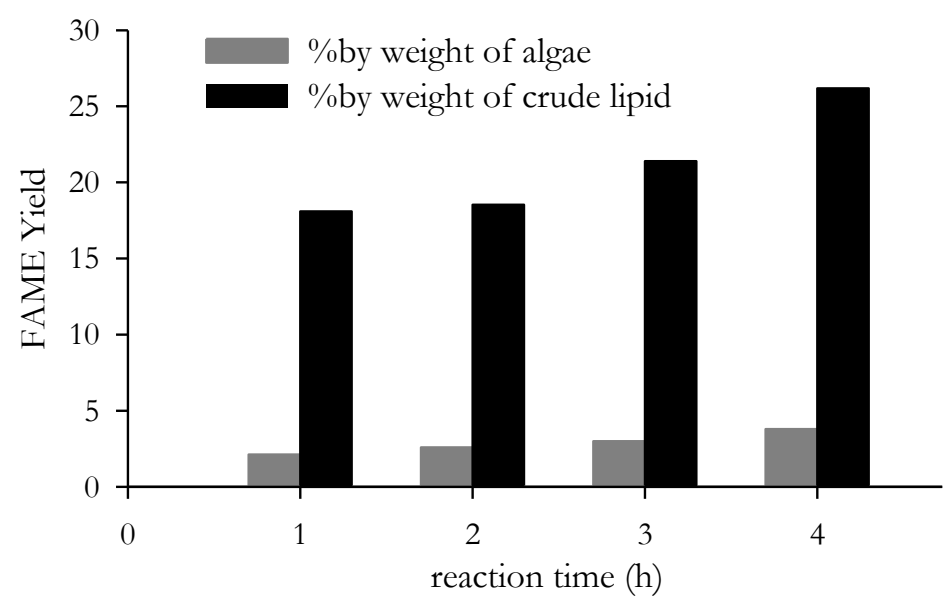

Fig. 4. Effect of extraction time on biodiesel yield with fixed ratio of methanol to biomass of 16:1 and amount of catalyst of $4 \%$ (Replication of experiments was carried out for selected conditions. The standard deviations of FAME yields (\% by weight of lipid) vary from 0.8-3.0.)

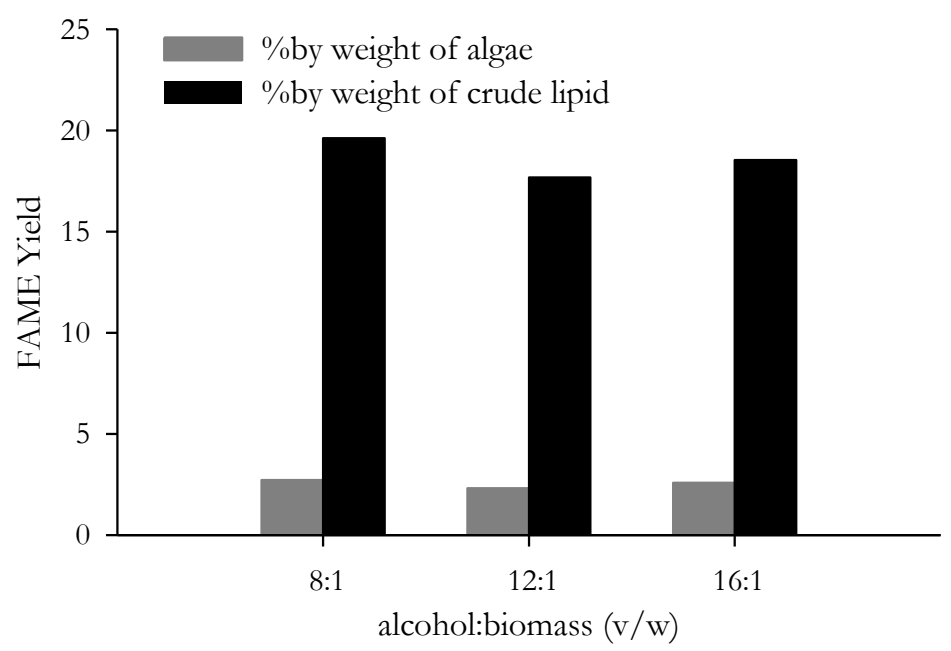

Fig. 5. Effect of alcohol to biomass ratio with fixed reaction time of $2 \mathrm{~h}$ and amount of catalyst of $4 \%$ (Replication of experiments were carried out for selected conditions. The standard deviations of FAME yields (\% by weight of lipid) vary from $0.8-3.0$.)

\subsubsection{Single-Step Biodiesel Production}

At the transesterification condition of $4 \%$ catalyst, 16:1 alcohol to biomass ratio and $4 \mathrm{~h}$ reaction time selected for this experiment, the performance of a single-step biodiesel production in comparison with that of the conventional two-step method. As shown in Fig 6, the yield of FAMEs obtained from the conventional method appeared to be significantly higher. This is inconsistent with Johnson and Wen, 2009 [4] which revealed that the greater yield was obtained by applying the single-step method with Schizochytrium limacinum. The reason is probably due to the different bio-characteristics of the microalgal strains. $S$. limacinum cell has thin cell walls [17] while the cell of $C$. vulgaris, used in this study, is enveloped by a thick cell wall, causing the mass transfer limitation that controls the reaction rate. This provides an evidence for the importance of the choice of algal strain. However, in this study, the condition of single-step biodiesel production has not yet been optimized. Regarding the previous result in section 3.2, the single-step process can probably be modified by applying microwave to assistant lipid extraction, and thus improving the yield. 


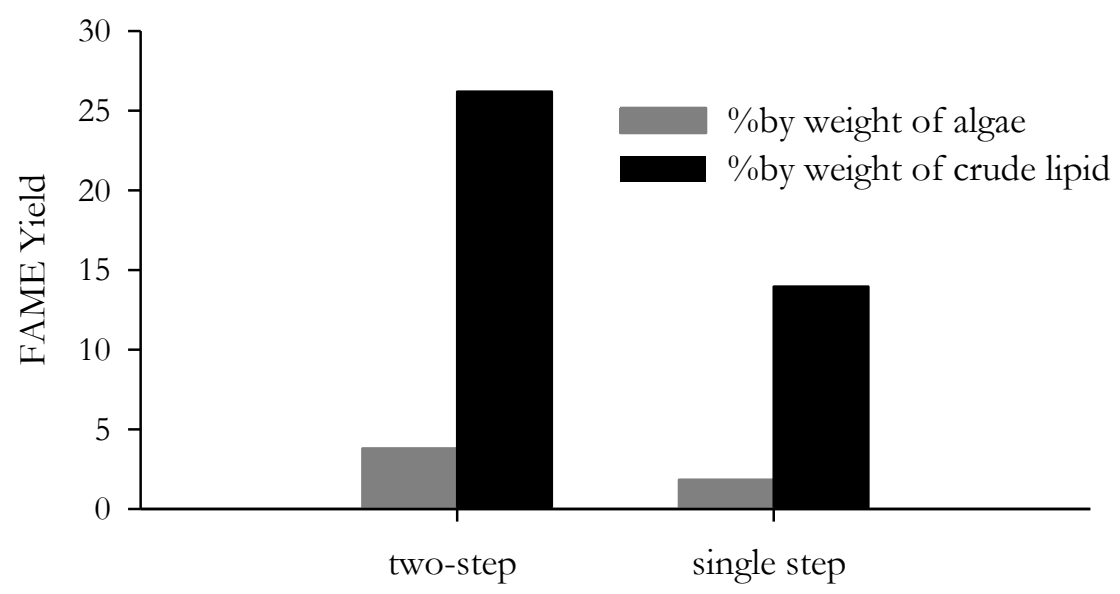

Fig. 6. Comparison of conventional two-step and single-step biodiesel production, with 4\% catalyst, 16:1 alcohol to biomass ratio and $4 \mathrm{~h}$ reaction time.

\section{Conclusions}

In summary, for the extraction of lipid from microalgae, $\mathrm{C} / \mathrm{M}$ gave the highest amount of extracted crude oil, while hexane could be a better choice in terms of providing more desirable content of glycerides. The selection of extraction method depends greatly on cell morphology such as the existence of thick cell walls. For example, for strains with tough cell wall such as C. vulgaris, without any prior cell disruption, as little as $70 \%$ of lipid was recovered even when extra time was given. On the other hand, for strains whose cell walls were previously damaged, neither UAE nor MAE gave additional benefits. Transesterification of Chlorella lipid could produce FAMEs similar in major components to biodiesel produced from crops. Based on the results of this study, $6 \%$ of catalyst, reaction time of $4 \mathrm{~h}$ and $16: 1$ alcohol to biomass ratio was found to produce the highest yield of biodiesel. In comparison to the conventional two-step method, the single-step biodiesel production from $C$. vulgaris provided lower biodiesel yield, possibly due to the thick cell walls.

\section{Acknowledgement}

This work was supported by Thailand Research Fund through The Royal Golden Jubilee Ph.D. Program (RGJ-TRF), Ratchadaphiseksomphot Endowment Fund (Chemical Engineering Research Unit for Value Adding of Bioresources, Chulalongkorn University) and PT'T Research and Technology Institute for the financial support.

\section{References}

[1] Y. Chisti, "Biodiesel from microalgae," Biotechnology Advances, vol. 25, pp. 294-306, 2007.

[2] L. F. Razon and R. R. Tan, "Net energy analysis of the production of biodiesel and biogas from the microalgae: Haematococcus pluvialis and Nannochloropsis," Applied Energy, vol. 88, pp. 3507-3514, 2011.

[3] J. Y. Lee, C. Yoo, S. Y. Jun, C. Y. Ahn, and H. M. Oh, "Comparison of several methods for effective lipid extraction from microalgae," Bioresource Technology, vol. 101, pp. 75-77, 2010.

[4] M. B. Johnson and Z. Wen, "Production of biodiesel fuel from the microalga Schizochytrium limacinum by direct transesterification of algal biomass," Energy \& Fuels, vol. 23, pp. 5179-5183, 2009.

[5] J. Folch, M. Lees, and G. H. Sloane-Stanley, "A simple method for the isolation and purification of total lipides from animal tissues," Journal of Biological Chemistry. vol. 226, pp. 497-509, 1957.

[6] W.W. Christie, Lipid Analysis, 2nd edn. Pergamon Press, New York,1982.

[7] AOAC 963.22, 969.33. Official Methods of Analysis. AOAC International, Gaithersburg, MD, USA., 2005. 
[8] A. Vieler, C. Wilhelm, R. Goss, R. Suß, and J. Schiller, "The lipid composition of the unicellular green alga Chlamydomonas reinhardtii and the diatom Cyclotella meneghiniana investigated by MALDITOF MS and TLC," Chemistry and Physics of Lipids, vol. 150, pp. 143-155, 2007.

[9] M. Zhu, P. P. Zhou, and L. J. Yu, "Extraction of lipids from Mortierella alpina and enrichment of arachidonic acid from the fungal lipids," Bioresource Technology, vol. 84, pp. 93-95, 2002.

[10] A. Widjaja, C. C. Chien, and Y. H. Ju, "Study of increasing lipid production from fresh water microalgae Chlorella vulgaris," Journal of the Taiwan Institute of Chemical Engineers, vol. 40, pp. 13 20, 2009.

[11] E. S. Umdu, M. Tuncer, and E. Seker, "Transesterification of Nannochloropsis oculata microalga's lipid to biodiesel on $\mathrm{Al} 2 \mathrm{O} 3$ supported $\mathrm{CaO}$ and $\mathrm{MgO}$ catalysts," Bioresource Technology, vol.100, pp. 2828-283, 2009

[12] X. Miao and Q. Wu, "Biodiesel production from heterotrophic microalgal oil," Bioresource Technology, vol. 97, pp. 841-846, 2006

[13] H. A. Metherel, Y. A. Taha, I. Hamid, and D. K. Stark, "The application of ultrasound energy to increase lipid extraction throughput of solid matrix samples (flaxseed)," Prostaglandins Leukot Essent Fatty Acids, vol. 81, pp. 417-423, 2009.

[14] G. Knothe, “"Designer" biodiesel: optimizing fatty ester composition to improve fuel properties," Energy \& Fuels, vol. 22, pp. 1358-1364, 2008.

[15] M. G. Montes D’Oca, C. V. Vie`gas, J. S. Lemo`es, E. K. Miyasaki, J. A. Moro’n-Villarreyes, E. G. Primel, and P. C. Abreu, "Production of FAMEs from several microalgal lipidic extracts and direct transesterification of the Chlorella pyrenoidosa," Biomass \& Bioenergy, vol. 35, pp. 1533-1538, 2011.

[16] N. Jomtib, C. Prommuak, M. Goto, M. Sasaki, and A. Shotipruk, "Effect of co-solvents on transesterification of refined palm oil in supercritical methanol," Engineering Journal, vol. 15, pp. 4958, 2011.

[17] D. Honda, T. Yokochi, T. Nakahara, S. Raghukumar, A. Nakagiri, K. Schaumann, and T. Higashihara, "Molecular phylogeny of Labyrinthulids and Thraustochytrids based on the sequencing of $18 \mathrm{~s}$ ribosomal RNA gene,” Journal of Eukaryotic Microbiology, vol. 46, pp. 637-647, 1999. 